\title{
Research on the Building Water Supply and Drainage System Energy Saving Methodology based on Structure Optimization
}

\author{
Xiaofeng Wang ${ }^{1}$ \\ ${ }^{1}$ College of Civil Engineering And Urban Construction, Jiujiang University, \\ Jiujiang,Jiangxi, 332005 China
}

\begin{abstract}
In this paper, we conduct theoretical research on the building water supply and drainage system energy saving methodology based on structure optimization. The construction and use of the building are consumed water sources and water has become the problem of the world's attention. Currently involved in building energy saving standards of water supply and drainage is not much, but with the improvement of energy requirements. Our designed methodology could enhance the energy saving performance of the current buildings which will has special and significant meaning.
\end{abstract}

Keywords: Structure optimization; Energy Saving; Water Supply and Drainage System.

\section{Introduction}

Building water supply and drainage design is a key link in the whole process of engineering construction, building water supply and drainage design standard is the technical basis of the design personnel to carry on the design correct understanding and application of standard of building water supply and drainage design is the designers to design the conform to the requirement of the construction control system of quality standard, reasonable and can achieve expected to use a function key. The rapid development of social economy, water supply and drainage energy saving technology is imperative. The construction and use of the building are consumed water sources and water has become the problem of the world's attention. In the face of the world energy conservation and environmental protection problems, we should advocate the building water supply and drainage energy saving design and reduce the pollutant emissions, improve the living environment to improve the living standard, the effective measures to improve the quality of life. Building energy efficiency design standard is the basic technical basis, the construction energy conservation construction is the basic requirement of building energy conservation goals, including mandatory stipulation that the main energy saving measures, the thermal value of performance index, energy consumption index, which considering the demand of economic and social benefits, must be strictly implemented. Currently involved in building energy saving standards of water supply and drainage is not much, but with the improvement of energy requirements, building water supply and drainage energy saving will be gradually improved, the standard also will continue to improve.

The main way for building water supply and drainage energy saving could be summarized as the follows. (1) Cooling water and fire water supply and drainage. The appropriate cooling water recycles and raises the repeated utilization ratio of water. It can be used under the condition of the water supply conditions permit, river water, river water, lake water and sea water and underground water as circulating cooling water, etc. Choose the cooling tower. In the dry areas of low humidity of the air temperature, can be appropriately raises through the design and calculation of cooling water in and out of the water temperature difference, to reduce the circulation of water and energy consumption of circulating water pump, reduce circulation pipe diameter. 
Ensure that the distance between the cooling tower, and a good air distribution conditions, avoid affect the cooling effect of cooling tower. (2) Automatic control and measurement. Buildings should be set up in the water supply and drainage automation monitoring and control system. Variable frequency pump water supply appropriate uses pressure gauge control water pump speed at the end of the pipe network operation mode. In accordance with the need of different places and conditions of use, should strengthen the water supply of water metering. Housing should be set for individual water meter measuring water. Residential building energy-saving renovation should set points building heat metering and heating system control devices. (3) Water Supply Optimization. When variable frequency pump water supply is used, should first adopt variable frequency variable voltage variable flow water supply mode, its energy saving effect is better than frequency conversion constant pressure variable flow water supply way. When using frequency constant pressure variable flow, working pressure setting should be close to the pump running power frequency when the lower limit of effective section head. Solar hot water system of thermal energy re-uses and water-saving technology should also be combined with each other [1-3]. The solar water heater can be used as hot water preheating measure which can be in the front end of the other heat exchangers.

In this paper, we conduct theoretical research on the building water supply and drainage system energy saving methodology based on structure optimization. Energy saving measures should be in the economic benefit of construction as a whole, according to the different performance and economic benefit goals to reach the intended purpose and function. In energy conservation, economic problems must be considered and the energy-saving efficiency can be in energy saving system operation after a certain period to realize the economic returns. If the project of building water supply and drainage has obvious energy saving effect in technology, can make the necessary economic and technical analysis, if possible, use the technical measures. In the figure one, we illustrate the organization of energy saving water supply and drainage system. The detailed discussion will be conduct later.

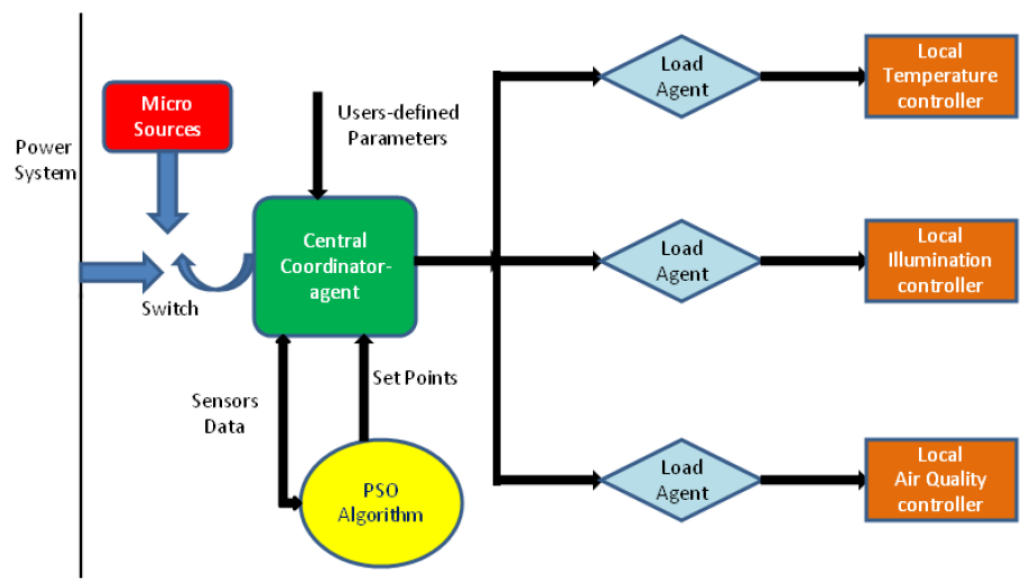

Figure 1. The Organization of Energy Saving Water Supply and Drainage System

\section{The Organization of Our Designed System}

The Water Supply Optimization. Building water supply and drainage as a branch of engineering and construction project of residents are inseparable part of daily life. If you can do it properly, will be in the water saving and energy saving operation of the whole society to make due contributions. We should optimize the water supply through the following 
aspects. (1) Using quadratic choosing reasonable partition pressurized water supply in the building water supply system. In high-rise buildings and municipal pressure cannot supply of buildings, the drinking water system design should be vertical zones. Each partition minimum sanitary ware water distribution point of hydrostatic should not be too big in parallel partition of water supply equipment should first adopt frequency conversion water supply equipment or pneumatic water supply equipment and energy-saving water supply equipment. For water supply equipment series partition preferable frequency control of motor speed pump. On the pipes material, should use water-saving energy-saving tubes, avoid the secondary pollution and affect water quality. (2) Control the head loss of water supply network and users with water pressure. In the design, optimization of pipe network layout, properly enlarge the most disadvantageous pipeline diameter when necessary, can reduce the pipe head loss, so as to achieve the effect of energy saving to achieve control of the water supply water system user some work pressure, you should understand the building use water facilities sanitary ware accessories required working pressure, water supply, the specification is often used in building water supply main sanitary ware accessories minimum working pressure make the rules. (3) Make full use of municipal water supply water pipe network pressure directly. We can guarantee the multi-store building. Water pressure can use municipal water supply directly. Buildings, using secondary pressurized water supply in the municipal tap water layers on the bottom of the pipe network pressure range, also should use municipal water supply water pipe network pressure directly. To save or reduce the cost of water energy expenditure and water supply equipment investment. (4) Measurement and monitoring of water supply system. More sufficient power supply area which can use low electric energy as heat source, the preparation of hot water in the night. No matter in what way, must be from two aspects of economic applicability and technical reliability of this consideration, combined with the corresponding actual places, choice of different energy saving optimization combination. Through the relevant departments of the operation of the pump in water supply system, the key water control valves, large equipment, such as tank water level monitoring. (5) Use the solar energy. Solar energy, for example, solar water heating system can be combined with water saving technology, reasonable design of hot water supply systems, make preheating can get better recycling. Where conditions permit, you can use the preparation of steam and hot water boiler heat source, or use a gas hot water units and other direct supply need hot water in the life. (6) Use water-saving sanitary ware in the design of building water supply system is one of the most effective water-saving measures. Should be used according to different places and in the use of water right of water-saving products, such as in the public toilet, lavatory appropriate uses induction faucet. Urinal water-saving products, such as appropriate uses induction flush valve is to prevent cross infection.

The Drainage optimization. Application of energy saving in building water supply and drainage technology as a comprehensive application engineering technology, at the time of application must be used according to the actual situation, must meet the requirements of building water supply and drainage design basic function under the premise of saving energy technology, we cannot blindly to pursue energy conservation, to attend, did not meet the requirements of building water supply and drainage design basic functions of energy saving are meaningless. Drainage should be using gravity drainage way, as far as possible and appropriate nearby emissions, avoid pressure increase. Appropriate uses rainwater and sewage, waste water distribution systems, is advantageous to the sewage and rainwater, wastewater recycling. (1) Rain sewage diversion. Appropriate uses rainwater and sewage drainage 
system shunt, sewage and waste water can make the same set of pipe system. Basement leakage, refrigerator condensed water and fire water drainage through different sump cleaning wastewater by submersible sewage pump discharge, the need to level control pump startup. Sewage flows through the courtyard sewage pipe network and septic tank treatment and then discharged into the municipal sewage pipe network. (2) Pipe set. All toilet drainage branch pipe is Ann in this level, complex building and residential building special ventilation tube, indoor drainage minimum diameter appropriate chooses DN75, ensures that each user privacy already so, also avoid pipeline leakage phenomenon. As far as possible when design the riser located outdoors or far away from the bedroom and sitting room to avoid the pipeline noise problems, all of the main design should try to reduce the noise reduction, for the user to create a clean environment. (3) Water and fire water supply and drainage. The appropriate cooling water recycling, in order to improve the repetition utilization of water which can be used under the condition of the water supply conditions permit, river water, river water, lake water as circulating cooling water, etc. Choose the cooling tower: in dry areas, low air wet bulb temperature of cooling water can be improved through the design calculation to the appropriate in and out of the temperature difference. To reduce the circulation of water and energy consumption of circulating water pump, reduce circulation pipe diameter. Reasonable arrangement of cooling tower: ensure that the distance between the cooling towers which have the good air distribution conditions. Avoid affect the cooling effect of cooling tower. (4) Through rainwater harvesting rainwater collection device, again through the subsequent water treatment facilities and water treatment reagent, eventually make the processed of rainwater in some water quality indicators, the rainwater recycling process is rainwater utilization system. After processing, the rain just like water, can be used as special can be a kind of water resources, the rainwater to flush toilets, green city, at the same time also can be used as a landscape water and other water with water quality standards, etc., such not only can reduce the have certain effect to the urban water consumption, at the same time with respect to the reduction of sewage treatment costs also have a certain effect.

The Hot Water and Other Resources Optimization. According to the specification, should first use of industrial waste heat, waste heat, geothermal and solar energy as heat source of centralized hot water supply systems. At the same time circulation piping should be arranged with routine way. At the same time also can provide convenient hot water supply. Solar energy is no pollution of clean energy. And inexhaustible, but also easy to use, heat conversion efficiency higher advantages. The rational selection of heat source living hot water system in water supply and drainage energy saving building has a very important role. Solar energy is a kind of abundant and can be widely used heat source, and the solar water heater is one of the most commonly used solar energy utilization device, can be used as hot water bath and heating heat source, has the very good economic benefits.

The Prospect and the Management of the System. Building water supply and drainage energy saving not only at the design stage, should also strengthen the combination and operation management, because in the actual use, the system management and maintenance is essential in energy saving. Operation management unit should be regularly used for buildings can system to do the necessary maintenance update preventive maintenance, inspection and replacement, discovery system failure should be resolved timely, let uses can run system under the state of energy saving, energy saving, can use the system not only can't possibly consume large amounts of energy. According to the different energy systems can also be a reasonable arrangement of the running time and way also is a means of saving energy. 
Energy is the important foundation of human survival and development, the development of economy depends on the development of energy. In recent years, with the energy crisis worsen, water gradually nervous, for the protection of water resources, water use and sewage disposal by countries around the world. In the field of construction, test whether building energy conservation measure is the water supply and drainage design how can achieve energy saving, therefore, do a good job in water supply and drainage energy saving design is very necessary, it has significance to the building water supply and drainage energy saving design. On the premise of meet the requirements of reasonable and comfortable, building water supply and drainage energy saving design through technology to reduce water consumption, improve the efficiency of water use, to meet the requirements of building water supply and drainage energy saving.

\section{Conclusion}

In this paper, we conduct theoretical research on the building water supply and drainage system energy saving methodology based on structure optimization. The application of energy saving in building water supply and drainage construction to improve the construction level of the entire construction projects, so as a construction enterprise, to fully realize the importance of energy saving in water supply and drainage construction application, and strengthen the analysis and study of energy saving, continuous research and development of new technology, new equipment, its application in water supply and drainage construction, only in this way can enhance the level of building water supply and drainage construction unceasingly, so as to meet the needs of modern social development. Our method provides the institutes with a novel way of saving energy which will be necessary.

\section{References}

[1] Xing J C, She X I. Discussion and Analysis on Energy-saving Optimization Design of Water Supply System for Passenger Train[J]. Railway Standard Design, 2013.

[2] Shi J D. Discussion on Urgency of Energy Saving and the Environmental Protection and Measures for the Building's Water Supply and Drainage System[J]. Gansu Metallurgy, 2011.

[3] Fei W U. On Exploration of Water-Saving and Energy-Saving Approaches of Building Water Supply and Drainage[J]. Journal of Hunan Environment-Biological Polytechnic, 